J. Dairy Sci. 96:4965-4976

http://dx.doi.org/10.3168/jds.2012-5713

(C) American Dairy Science Association ${ }^{\circledR}, 2013$.

\title{
Herd-level relationship between antimicrobial use and presence or absence of antimicrobial resistance in gram-negative bovine mastitis pathogens on Canadian dairy farms
}

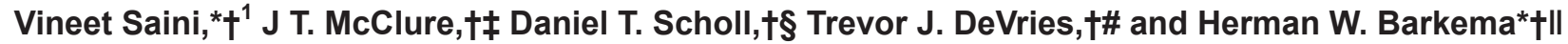 \\ *Department of Production Animal Health, University of Calgary, Calgary, Alberta, T2N 4N1, Canada \\ †Canadian Bovine Mastitis Research Network, C. P. 5000, Saint-Hyacinthe, Québec, J2S 7C6, Canada \\ ‡Department of Health Management, Atlantic Veterinary College, University of Prince Edward Island, Charlottetown, Prince Edward Island, \\ C1A 4P3, Canada \\ §South Dakota Agricultural Experiment Station, South Dakota State University, Brookings 57007 \\ \#Department of Animal and Poultry Science, University of Guelph, Kemptville Campus, Kemptville, Ontario, K0G 1J0, Canada \\ \|Department of Reproduction, Obstetrics and Herd Health, Ghent University, Merelbeke, Belgium
}

\begin{abstract}
Concurrent data on antimicrobial use (AMU) and resistance are needed to contain antimicrobial resistance (AMR) in bacteria. The present study examined a herd-level association between AMU and AMR in Escherichia coli $(\mathrm{n}=394)$ and Klebsiella species ( $\mathrm{n}=$ 139) isolated from bovine intramammary infections and mastitis cases on 89 dairy farms in 4 regions of Canada [Alberta, Ontario, Québec, and Maritime Provinces (Prince Edward Island, Nova Scotia, and New Brunswick)]. Antimicrobial use data were collected using inventory of empty antimicrobial containers and antimicrobial drug use rate was calculated to quantify herd-level AMU. Minimum inhibitory concentrations (MIC) were determined using Sensititre National Antimicrobial Resistance Monitoring System (NARMS) gram-negative MIC plate (Trek Diagnostic Systems Inc., Cleveland, OH). Isolates were classified as susceptible, intermediate, or resistant. Intermediate and resistant category isolates were combined to form an AMR category, and multivariable logistic regression models were built to determine herd-level odds of AMR to tetracycline, ampicillin, cefoxitin, chloramphenicol, trimethoprim-sulfamethoxazole combination, sulfisoxazole, streptomycin and kanamycin in E. coli isolates. In the case of Klebsiella species isolates, logistic regression models were built for tetracycline and sulfisoxazole; however, no associations between AMU and AMR in Klebsiella species were observed. Ampicillin-intermediate or -resistant E. coli isolates were associated with herds that used intramammarily administered cloxacillin, penicillin-novobiocin combination, and cephapirin used for dry cow therapy [odds ratios $(\mathrm{OR})=26,32$,
\end{abstract}

Received May 10, 2012.

Accepted April 14, 2013.

${ }^{1}$ Corresponding author: vineet.saini@albertahealthservices.ca and 189, respectively], and intramammary ceftiofur administered for lactating cow therapy and systemically administered penicillin $(\mathrm{OR}=162$ and 2.7, respectively). Use of systemically administered penicillin on a dairy farm was associated with tetracycline and streptomycin-intermediate or -resistant $E$. coli isolates (OR $=5.6$ and 2.8 , respectively). Use of cephapirin and cloxacillin administered intramammarily for dry cow therapy was associated with increasing odds of having at least 1 kanamycin-intermediate or -resistant $E$. coli isolate at a farm $(\mathrm{OR}=8.7$ and 9.3 , respectively). Use of systemically administered tetracycline and ceftiofur was associated with cefoxitin-intermediate or -resistant E. $\operatorname{coli}(\mathrm{OR}=0.13$ and 0.16 , respectively); however, the odds of a dairy herd having at least 1 cefoxitinintermediate or -resistant $E$. coli isolate due to systemically administered ceftiofur increased with increasing average herd parity $(\mathrm{OR}=3.1)$. Association between herd-level AMU and AMR in bovine mastitis coliforms was observed for certain antimicrobials. Differences in AMR between different barn types and geographical regions were not observed.

Key words: bovine mastitis, Escherichia coli, Klebsiella species, minimum inhibitory concentration

\section{INTRODUCTION}

Environmental mastitis in dairy cattle caused by coliforms occurs mostly in early lactation, with highproducing cows being overrepresented. Coliform mastitis can more often cause severe systemic signs and has a higher case-fatality rate compared with grampositive mastitis (Barkema et al., 1998). The majority of coliform mastitis cases are caused by Escherichia coli (Lehtolainen et al., 2003). Klebsiella is another coliform organism that is an emerging pathogen with rising incidence in North America (Zadoks and Munoz, 2007); Klebsiella was observed to be the most frequent clini- 
cal mastitis pathogen in freestall dairy cattle herds in Western Canada from 2003 to 2005 (Olde Riekerink et al., 2008). These gram-negative udder pathogens have been implicated in as low as $20 \%$ to more than $60 \%$ of clinical mastitis cases in different countries (Pyörälä and Honkanen-Buzalski, 1994; Shpigel et al., 1998).

Broad-spectrum antimicrobials are commonly used to treat coliform mastitis (Erskine et al., 2002), although no definitive evidence exists of the efficacy of antimicrobial treatment (Erskine et al., 1992; Pyörälä et al., 1994). Antimicrobial resistance (AMR) could be one potential reason for the lack of efficacy. Antimicrobials such as oxytetracycline, ceftiofur, ampicillin, and amoxicillin can potentially be administered for treating systemic signs due to coliform mastitis in lactating dairy cattle (Wagner and Erskine, 2006). However, AMR in bovine mastitis coliforms is commonly observed (Makovec and Ruegg, 2003). Researchers have evaluated the dynamics of AMR in coliforms isolated from the feces of young dairy calves, dairy cattle, beef cattle, and swine (Berge et al., 2005, 2010; Akwar et al., 2008; Checkley et al., 2008). Unfortunately, little information exists on the effect of therapeutic and prophylactic antimicrobial use (AMU) on AMR in bovine E. coli and Klebsiella species mastitis isolates (Srinivasan et al., 2007). Therefore, it is prudent to assess and evaluate the relationship between AMU and AMR in bovine mastitis coliforms. The objective of this study was to assess and evaluate a herd-level association between AMU and AMR in E. coli and Klebsiella species isolated from IMI and clinical and subclinical bovine mastitis cases on Canadian dairy farms.

\section{MATERIALS AND METHODS}

\section{Herd Selection}

Data for this study originated from the National Cohort of Dairy Farms of the Canadian Bovine Mastitis Research Network (CBMRN), which consisted of 91 commercial dairy farms located in 4 regions across Canada [Alberta, Ontario, Québec, and Maritime Provinces (Prince Edward Island, Nova Scotia, and New Brunswick)]. Herd-selection criteria for the present study have been described by Reyher et al. (2011). In short, dairy herds were selected to replicate the regional proportion of freestall systems to within 15 percentage points and to be uniformly distributed among 3 strata of the most recent 12-mo bulk tank SCC average $(\leq 150,000$ cells $/ \mathrm{mL},>150,000$ and $\leq 300,000$ cells $/ \mathrm{mL}$, and $>300,000$ cells $/ \mathrm{mL}$ ); herds with a milking schedule of 3 times per day and herds with less than $80 \%$ (or less than 15) Holstein-Friesian lactating and dry cows at the time of enrollment were excluded. Further, eligible dairy herds must have been participating in a DHI data collection program.

\section{AMU Assessment}

Antimicrobial use data collection has been described by Saini et al. (2012a). In short, AMU data were collected from February 2007 to December 2008. Fortyliter receptacles were placed on participating farms for collecting data for AMU. Producers, farm workers, and other farm personnel were instructed to deposit the empty containers of all drugs used by them or the veterinarian for treatment in calves, heifers, and adult cows (dry cows and lactating cows) into these receptacles.

Antimicrobial use data were quantified in units of animal defined-daily doses (ADD). The ADD (g/d) was defined as the average daily on-label dosage multiplied by the approximate weight of an adult dairy cow $(\mathrm{BW}=600 \mathrm{~kg}$; Jensen et al., 2004) and was based on the Canadian compendium of veterinary products. Further, antimicrobial drug use rate (ADUR) was defined as the number of ADD used on a farm per 1,000 cows (milking and dry) per day. The ADUR was the herdlevel estimate of AMU (Tables 1 and 2).

\section{Sampling and Bacterial Culturing}

Sampling and bacterial culturing of isolates have been described elsewhere (Saini et al., 2012b). In short, 3 different sets of milk samples were collected. The first set included milk samples from clinical mastitis cases. These samples were collected before and after antimicrobial treatment.

The second set included milk samples from nonclinical lactating cows; a subsample of 15 fresh and lactating cows was randomly selected per farm using a computer-driven method of random sampling without replacement.

The third set of milk samples were collected from another selected group of 15 cows that were expected to remain in the herd until at least 2 wk after calving. Samples were frozen at $-20^{\circ} \mathrm{C}$ and shipped to the regional Canadian Bovine Mastitis Research Network laboratory where bacterial culturing and identification, and somatic cell counting of the milk samples were done (Hogan et al., 1999).

Because multiple isolates could come from a single cow, it was decided to randomly include only 1 isolate per quarter using the computer-driven randomization process of sampling without replacement. The isolates comprised IMI and subclinical and clinical mastitis cases. Clinical mastitis was defined as an inflammation of the udder, leading to occurrence of flakes, clots, 
or other gross alterations in milk, whereas subclinical mastitis was defined as SCC >200,000 cells/mL from a cow without clinical signs of mastitis. Intramammary infection was defined as a culture-positive sample with a minimum number of colonies cultured per $0.01 \mathrm{~mL}$ of milk $\geq 1$ and without reference to SCC (Dohoo et al., 2011; Reyher et al., 2011).

\section{MIC Determination}

Antimicrobial susceptibility testing of bovine mastitis coliforms has been described elsewhere (Saini et al., 2012b). Minimum inhibitory concentrations of these isolates were determined using the Sensititre microdilution system (Trek Diagnostic Systems Inc., Cleveland, $\mathrm{OH})$. Sensititre National Antimicrobial Resistance Monitoring System (NARMS) gram-negative plates containing amikacin, gentamicin, kanamycin, streptomycin, ampicillin, amoxicillin-clavulanic acid combination (AMXCLA), cefoxitin, ceftriaxone, ceftiofur, chloramphenicol, ciprofloxacin, nalidixic acid, sulfisoxazole, trimethoprim-sulfamethoxazole (TMPS) combination, and tetracycline were used. Antimicrobial susceptibility testing was done as per manufacturer instructions (Trek Diagnostic Systems Inc.). The MIC values of various antimicrobial-isolate combinations were determined using the Sensititre Auto Reader. In the case of sulfadimethoxine, the MIC results were determined manually, as advised by Trek Diagnostic Systems Inc. The following reference strains were included in the study: E. coli ATCC 25922 and Klebsiella pneumonia ATCC 700603.

Minimum inhibitory concentration was defined as the lowest concentration of an antimicrobial that inhibited any visible growth of an isolate. In the case of an antimicrobial combination such as TMPS, the MIC of the first agent (trimethoprim) was reported as the MIC for the combination. Thereafter, the isolates were categorized as susceptible, intermediate, or resistant on the basis of Clinical and Laboratory Standards Institute (CLSI)based MIC breakpoints based on isolates of human and animal origin (CLSI, 2000, 2008). Intermediate isolates were combined with resistant isolates to form an AMR category for the sake of statistical analysis.

\section{Statistical Analyses}

Antimicrobial use data were entered into a customized database (Microsoft Office Access 2006; Microsoft Corp., Redmond, WA). A random sample of the drug tally sheets $(25 \%)$ was checked manually to detect errors in data entry; however, no errors were detected. Data analyses were performed using Intercooled Stata 11.1 software (Intercooled Stata for Macintosh, version 
Table 2. Stratified analysis of herd-level antimicrobial drug use rate [animal defined-daily doses (ADD)/1,000 cow-days] of various antimicrobial drug classes used across 76 dairy farms with Escherichia coli isolates in 6 Canadian provinces

\begin{tabular}{|c|c|c|c|c|c|c|}
\hline Independent variable & Description & Mean & SEM & Minimum & Median & Maximum \\
\hline \multicolumn{7}{|c|}{ Herds with susceptible isolates $(\mathrm{n}=36)$} \\
\hline Cloxacillin & Intramammary use (dry cow therapy) & 0.41 & 0.10 & 0 & 0.03 & 1.93 \\
\hline Cephapirin & Intramammary use (dry cow therapy) & 0.32 & 0.09 & 0 & 0 & 1.92 \\
\hline Penicillin-novobiocin combination & Intramammary use (dry cow therapy) & 0.73 & 0.14 & 0 & 0.20 & 2.56 \\
\hline Cephapirin & Intramammary use (lactating cow therapy) & 0.46 & 0.13 & 0 & 0.20 & 4.49 \\
\hline Ceftiofur & Intramammary use (lactating cow therapy) & 0.05 & 0.01 & 0 & 0 & 0.32 \\
\hline Penicillin combination ${ }^{1}$ & Intramammary use (lactating cow therapy) & 1.94 & 0.23 & 0 & 1.93 & 6.38 \\
\hline Pirlimycin & Intramammary use (lactating cow therapy) & 0.61 & 0.22 & 0 & 0.06 & 6.73 \\
\hline Ceftiofur & Systemic use & 1.79 & 0.28 & 0 & 1.22 & 7.09 \\
\hline Penicillin & Systemic use & 0.81 & 0.13 & 0 & 0.57 & 2.53 \\
\hline Tetracycline & Systemic use & 0.85 & 0.16 & 0 & 0.44 & 4.13 \\
\hline TMP-sulfadoxine combination ${ }^{2}$ & Systemic use & 0.79 & 0.16 & 0 & 0.42 & 3.75 \\
\hline Florfenicol & Systemic use & 0.15 & 0.04 & 0 & 0 & 1.14 \\
\hline Erythromycin & Systemic use & 0.46 & 0.18 & 0 & 0 & 5.41 \\
\hline \multicolumn{7}{|c|}{ Herds with intermediate or resistant isolates $(\mathrm{n}=40)$} \\
\hline Cloxacillin & Intramammary use (dry cow therapy) & 0.48 & 0.10 & 0 & 0.12 & 2.00 \\
\hline Cephapirin & Intramammary use (dry cow therapy) & 0.25 & 0.07 & 0 & 0 & 1.71 \\
\hline Penicillin-novobiocin combination & Intramammary use (dry cow therapy) & 0.92 & 0.13 & 0 & 0.77 & 2.37 \\
\hline Cephapirin & Intramammary use (lactating cow therapy) & 0.78 & 0.19 & 0 & 0.41 & 6.66 \\
\hline Ceftiofur & Intramammary use (lactating cow therapy) & 0.16 & 0.04 & 0 & 0 & 1.19 \\
\hline Penicillin combination $^{1}$ & Intramammary use (lactating cow therapy) & 2.88 & 0.59 & 0.03 & 1.65 & 19.68 \\
\hline Pirlimycin & Intramammary use (lactating cow therapy) & 0.81 & 0.27 & 0 & 0.06 & 8.91 \\
\hline Ceftiofur & Systemic use & 2.22 & 0.30 & 0 & 1.72 & 6.45 \\
\hline Penicillin & Systemic use & 1.64 & 0.21 & 0 & 1.29 & 5.24 \\
\hline Tetracycline & Systemic use & 0.59 & 0.16 & 0 & 0.18 & 3.93 \\
\hline TMP-sulfadoxine combination & Systemic use & 1.09 & 0.17 & 0 & 0.61 & 3.96 \\
\hline Florfenicol & Systemic use & 0.15 & 0.04 & 0 & 0 & 1.21 \\
\hline Erythromycin & Systemic use & 0.09 & 0.03 & 0 & 0 & 0.78 \\
\hline
\end{tabular}

${ }^{1}$ Intramammary preparation containing penicillin G procaine, dihydrostreptomycin sulfate, novobiocin sodium, and polymyxin B sulfate.

${ }^{2} \mathrm{TMP}=$ trimethoprim 
11.1; Stata Corp., College Station, TX). For analytical purposes, the unit of analysis was AMR (intermediate or resistant) at the herd level (0: number of intermediate or resistant isolates at a farm $=0 ; 1$ : number of intermediate or resistant isolates at a farm $\geq 1$ ). The herd-level prevalence percentage of AMR (intermediate or resistant isolates) was calculated and defined as the percentage of total number of herds with AMR (intermediate or resistant) isolates divided by the total number of herds sampled.

All the following independent variables were screened based on descriptive statistics (means, variances, percentiles for continuous variables, and frequency tabulations for categorical variables): antimicrobial use (estimated as ADUR), region, herd average milk production, barn type, herd average SCC, herd average parity, average herd size, and number of isolates sampled at a farm (Dohoo et al., 2009). Subsequently, these independent variables were screened for univariate associations using the likelihood ratio test statistic (Hosmer and Lemeshow, 2000). Variables significant at $P \leq 0.25$ were eligible for inclusion in the multivariable logistic regression models. Using backward elimination, variables were retained in the model only if significant at $P \leq 0.05$, unless exclusion resulted in significant change in deviance. Thereafter, any variables not selected for the original multivariable model were added back into the model to identify variables that were not significantly associated with the herd-level outcome, but made an important contribution in the presence of other variables (distorter variables). Barn type, region, average herd size, and average herd parity were considered a priori as potential confounders. Variables such as average herd SCC, herd average milk production per cow, average herd size, and average herd parity were centered at their respective lowest values for sensible interpretation of the intercept value.

The assumption of linearity in the logit of herd-level AMR outcome for continuous variables was evaluated graphically using lowess smoother scatter plots (Dohoo et al., 2009) and then by using fractional polynomials command in Intercooled Stata 11.1 software. Two-way interaction terms were added one at a time to the main effects model and retained at $P \leq 0.05$ unless exclusion resulted in significant change in deviance. Clustering of farms within a region was assessed by calculating the intraclass correlation coefficient; however, no clustering was observed. In the case of nominal variables such as region, the baseline/referent level was selected as the one with sufficiently large sample size (Dohoo et al., 2009).

Multivariable logistic regression models were built for the following AMR (intermediate or resistant) outcomes in E. coli isolates: tetracycline, ampicil- lin, cefoxitin, chloramphenicol, TMPS, sulfisoxazole, streptomycin, and kanamycin (Table 3). In the case of Klebsiella species isolates, logistic regression models were built for tetracycline and sulfisoxazole; however, all the predictors were statistically nonsignificant. The model could not be built for ampicillin, as Klebsiella species are intrinsically resistant. Models could not be built for remaining antimicrobials due to low prevalence/absence of AMR (intermediate or resistant) in gram-negative bovine mastitis pathogens (Table 3 and 4). The assessment of fit of the models was done based on the Hosmer-Lemeshow goodness-of-fit test, and generalized linear models-defined residuals (Dohoo et al., 2009).

\section{RESULTS}

\section{Antimicrobial Resistance Proportion Estimates}

Minimum inhibitory concentration values were determined for $394 \mathrm{E}$. coli isolates that came from 394 quarters of 353 cows on 76 dairy farms. A total of 38/394 $E$. coli isolates came from milk samples obtained from subclinical mastitis cases. The total number of isolates intermediate or resistant to 1 or more antimicrobials was 70 , or a prevalence of $17.7 \%$ (95\% CI: 14.1 to $21.9 \%$ ). The total number of isolates intermediate or resistant to an antimicrobial ranged from 0 to 6 per farm. The proportion of herds with at least 1 intermediate or resistant $E$. coli isolate ranged from $0 \%$ for ceftriaxone and ciprofloxacin to $38.1 \%$ for tetracycline (Table 3).

In the case of Klebsiella species, MIC values were determined for 139 isolates that came from 139 quarters of 114 cows on 37 dairy farms. A total of 18/139 Klebsiella spp. isolates came from milk samples obtained from subclinical mastitis cases. Fifty-one isolates or $36.6 \%$ (95\% CI: 28.6 to $45.2 \%$ ) were intermediate or resistant to 1 or more antimicrobials. The total number of isolates intermediate or resistant to an antimicrobial ranged from 0 to 1 per farm. The proportion of herds with at least 1 intermediate or resistant Klebsiella species isolate ranged from $0 \%$ for amikacin, ceftiofur, ceftriaxone, ciprofloxacin, and nalidixic acid to $24.3 \%$ for tetracycline (Table 4).

\section{Multivariable Analysis}

Systemically administered tetracycline use tended to decrease the odds of having at least 1 tetracyclineintermediate or -resistant $E$. coli isolate at a dairy farm (Table 5). The use of systemically administered penicillin was associated with increasing odds of having at least 1 tetracycline-intermediate or -resistant $E$. coli isolate at a dairy farm. The odds of having at least 1 
Table 3. Descriptive statistics of herd-level antimicrobial resistance outcomes in Escherichia coli $(\mathrm{n}=394)$ isolated from bovine IMI and (sub)clinical mastitis cases on 76 dairy farms across 6 provinces in Canada

\begin{tabular}{|c|c|c|c|c|c|c|c|}
\hline $\begin{array}{l}\text { Resistance } \\
\text { outcome }\end{array}$ & $\begin{array}{c}\text { Herds }^{1} \\
{[\text { no. }(\%)]}\end{array}$ & $\begin{array}{l}\text { Isolates }^{2} \\
\text { (no.) }\end{array}$ & $\begin{array}{c}\text { Mean }^{3} \\
\text { (no.) }\end{array}$ & SEM & Minimum & Median & Maximum \\
\hline Amikacin & $2(2.6)$ & 2 & 0.02 & 0.01 & 0 & 0 & 1 \\
\hline Ampicillin & $24(31.5)$ & 38 & 0.50 & 0.09 & 0 & 0 & 3 \\
\hline Amoxi-CLA ${ }^{4}$ & $7(9.2)$ & 13 & 0.17 & 0.06 & 0 & 0 & 3 \\
\hline Cefoxitin & $11(14.4)$ & 16 & 0.21 & 0.07 & 0 & 0 & 5 \\
\hline Ceftriaxone & 0 & 0 & - & - & - & - & - \\
\hline Ceftiofur & $4(5.2)$ & 5 & 0.06 & 0.03 & 0 & 0 & 2 \\
\hline Chloramphenicol & $10(13.1)$ & 16 & 0.21 & 0.07 & 0 & 0 & 3 \\
\hline Gentamicin & $2(2.6)$ & 2 & 0.02 & 0.01 & 0 & 0 & 1 \\
\hline Kanamycin & $13(17.1)$ & 18 & 0.23 & 0.06 & 0 & 0 & 3 \\
\hline Streptomycin & $24(31.5)$ & 34 & 0.44 & 0.09 & 0 & 0 & 4 \\
\hline Ciprofloxacin & 0 & 0 & - & - & - & - & - \\
\hline Nalidixic acid & $1(1.3)$ & 1 & 0.01 & 0.01 & 0 & 0 & 1 \\
\hline Sulfisoxazole & $21(27.6)$ & 36 & 0.47 & 0.10 & 0 & 0 & 4 \\
\hline TMP-sulfa ${ }^{5}$ & $14(18.4)$ & 22 & 0.28 & 0.08 & 0 & 0 & 3 \\
\hline Tetracycline & $29(38.1)$ & 57 & 0.75 & 0.15 & 0 & 0 & 6 \\
\hline
\end{tabular}

${ }^{1}$ Number of herds with at least 1 Escherichia coli isolate that was classified as intermediate or resistant.

${ }^{2}$ Number of Escherichia coli isolates that were classified as intermediate or resistant.

${ }^{3}$ Average number of Escherichia coli isolates per farm that were classified as intermediate or resistant.

${ }^{4}$ Amoxicillin-clavulanic acid combination

${ }^{5} \mathrm{TMP}=$ trimethoprim.

ampicillin-intermediate or -resistant E. coli isolate at a dairy farm increased with increasing use of ceftiofur administered intramammarily for lactating cow therapy; penicillin-novobiocin, cloxacillin, and cephapirin administered intramammarily for dry cow therapy; and systemically administered penicillin (Table 5).

The odds of having at least 1 streptomycin-intermediate or -resistant E. coli isolate at a dairy farm increased with increasing use of systemically administered penicillin; however, the odds decreased with increasing use of systemically administered tetracycline at a dairy farm (Table 6). The use of cephapirin and cloxacillin administered intramammarily for dry cow therapy was associated with increasing odds of having at least 1 kanamycin-intermediate or -resistant $E$. coli isolate at a dairy farm (Table 6).

An increase in the use of ceftiofur administered intramammarily for lactating cow therapy was associated with increasing odds of having at least 1 TMPSintermediate or -resistant E. coli isolate at a dairy farm (Table 6). The odds increased with an increasing use of penicillin combination administered intramammar-

Table 4. Descriptive statistics of herd-level antimicrobial resistance outcomes in Klebsiella species $(\mathrm{n}=139)$ isolated from bovine IMI and (sub)clinical mastitis cases on 37 dairy farms across 6 provinces in Canada

\begin{tabular}{|c|c|c|c|c|c|c|c|}
\hline $\begin{array}{l}\text { Resistance } \\
\text { outcome }\end{array}$ & $\begin{array}{c}\text { Herds }^{1} \\
{[\text { no. }(\%)]}\end{array}$ & $\begin{array}{l}\text { Isolates }^{2} \\
\text { (no.) }\end{array}$ & $\begin{array}{c}\text { Mean }^{3} \\
(\text { no. })\end{array}$ & SEM & Minimum & Median & Maximum \\
\hline Amikacin & 0 & 0 & - & - & - & - & - \\
\hline \multicolumn{8}{|l|}{ Intrinsic resistance } \\
\hline Amoxi-CLA $^{4}$ & $4(10.8)$ & 9 & 0.10 & 0.05 & 0 & 0 & 1 \\
\hline Cefoxitin & $5(13.5)$ & 10 & 0.13 & 0.05 & 0 & 0 & 1 \\
\hline Ceftriaxone & 0 & 0 & - & - & - & - & - \\
\hline Ceftiofur & 0 & 0 & - & - & - & - & - \\
\hline Chloramphenicol & $3(8.1)$ & 4 & 0.08 & 0.04 & 0 & 0 & 1 \\
\hline Gentamicin & $1(2.7)$ & 2 & 0.02 & 0.02 & 0 & 0 & 1 \\
\hline Kanamycin & $6(16.2)$ & 9 & 0.16 & 0.06 & 0 & 0 & 1 \\
\hline Streptomycin & $7(18.9)$ & 21 & 0.18 & 0.06 & 0 & 0 & 1 \\
\hline Ciprofloxacin & 0 & 0 & - & - & - & - & - \\
\hline Nalidixic acid & 0 & 0 & - & - & - & - & - \\
\hline Sulfisoxazole & $8(21.6)$ & 17 & 0.21 & 0.06 & 0 & 0 & 1 \\
\hline TMP-sulfa ${ }^{5}$ & $2(5.4)$ & 3 & 0.05 & 0.03 & 0 & 0 & 1 \\
\hline Tetracycline & $9(24.3)$ & 28 & 0.24 & 0.04 & 0 & 0 & 1 \\
\hline
\end{tabular}

${ }^{1}$ Number of herds with at least 1 Klebsiella species isolate that was classified as intermediate or resistant.

${ }^{2}$ Number of Klebsiella species isolates that were classified as intermediate or resistant.

${ }^{3}$ Average number of Klebsiella species isolates per farm that were classified as intermediate or resistant.

${ }^{4}$ Amoxicillin-clavulanic acid combination.

${ }^{5} \mathrm{TMP}=$ trimethoprim. 
Table 5. Final logistic regression models depicting herd-level association between antimicrobial use and antimicrobial resistance to tetracycline and ampicillin in Escherichia coli $(\mathrm{n}=394)$ isolated from bovine IMI and (sub)clinical mastitis cases on 76 dairy farms in 6 Canadian provinces

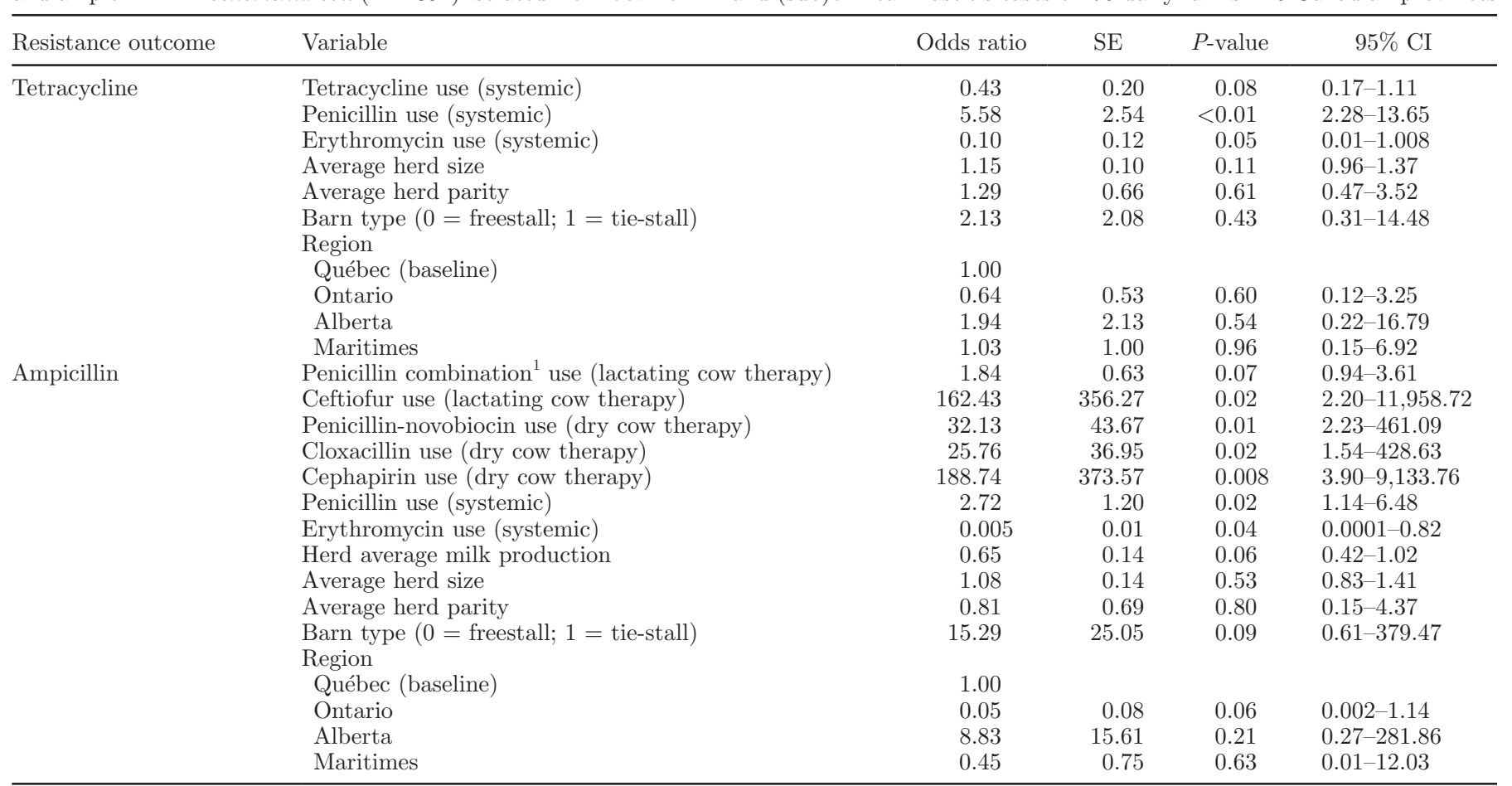

${ }^{1}$ Intramammary preparation containing penicillin G procaine, dihydrostreptomycin sulfate, novobiocin sodium, and polymyxin B sulfate.

ily for lactating cow therapy. However, the impact of penicillin combination use on having an intermediate or resistant TMPS isolate decreased with an increase in average herd size (i.e., larger dairy farms had lower odds of having TMPS-intermediate or -resistant E. coli isolates due to penicillin combination use compared with smaller dairy farms). The odds of a herd having at least 1 sulfisoxazole-intermediate or -resistant E. coli isolate increased with increasing use of systemically administered TMPS. However, the odds due to systemically administered TMPS decreased with increasing average herd size (Table 6).

The odds of a dairy herd having at least 1 cefoxitinintermediate or -resistant $E$. coli isolate decreased with increasing use of systemically administered ceftiofur and tetracycline; however, the odds of cefoxitin-intermediate or -resistant isolates due to systemically administered ceftiofur increased with increasing average herd parity (Table 7). The use of systemically administered tetracycline was associated with decreasing odds of having chloramphenicol-intermediate or -resistant $E$. coli isolates (Table 7).

\section{DISCUSSION}

This is the first time that a Canada-wide study was conducted to determine herd-level risk factors of AMR outcome (intermediate or resistant) in gram-negative bovine mastitis pathogens. Selected dairy herds were representative of their respective geographical dairy herd populations in some important parameters (Reyher et al., 2011). In addition to AMU, data were collected on herd-level variables such as SCC, milk production, barn type, herd size, and geographical region that could potentially explain variation in AMR outcome (intermediate or resistant) at the herd level. In general, herds with intermediate or resistant isolates had higher ADUR of various antimicrobial drug classes compared with the herds with susceptible isolates. Herds were not classified as users or nonusers, or low users or high users of an antimicrobial class on the basis of ADUR in this study. Such classification presumes that low ADUR (e.g., $1 \mathrm{ADD} / 1,000$ cows per day) or high ADUR (e.g., $3 \mathrm{ADD} / 1,000$ cows per day) of an antimicrobial class at a dairy farm has a similar effect on AMR, which is however not true. Therefore, ADUR was modeled as a continuous variable to measure the dose-response relationship between herd-level AMU and AMR outcome (intermediate or resistant). It was not possible to include average number of posttreatment isolates per herd (as a measure of recent exposure to an antimicrobial) as an independent predictor in the model, because (a) the total number of isolates per herd was not a significant predictor overall and, hence, a subgroup 
Table 6. Final logistic regression models depicting herd-level association between antimicrobial use and antimicrobial resistance to streptomycin and trimethoprim-sulfamethoxazole (TMPS) combination in Escherichia coli $(\mathrm{n}=394)$ isolated from bovine IMI and (sub)clinical mastitis cases on 76 dairy farms in 6 Canadian provinces

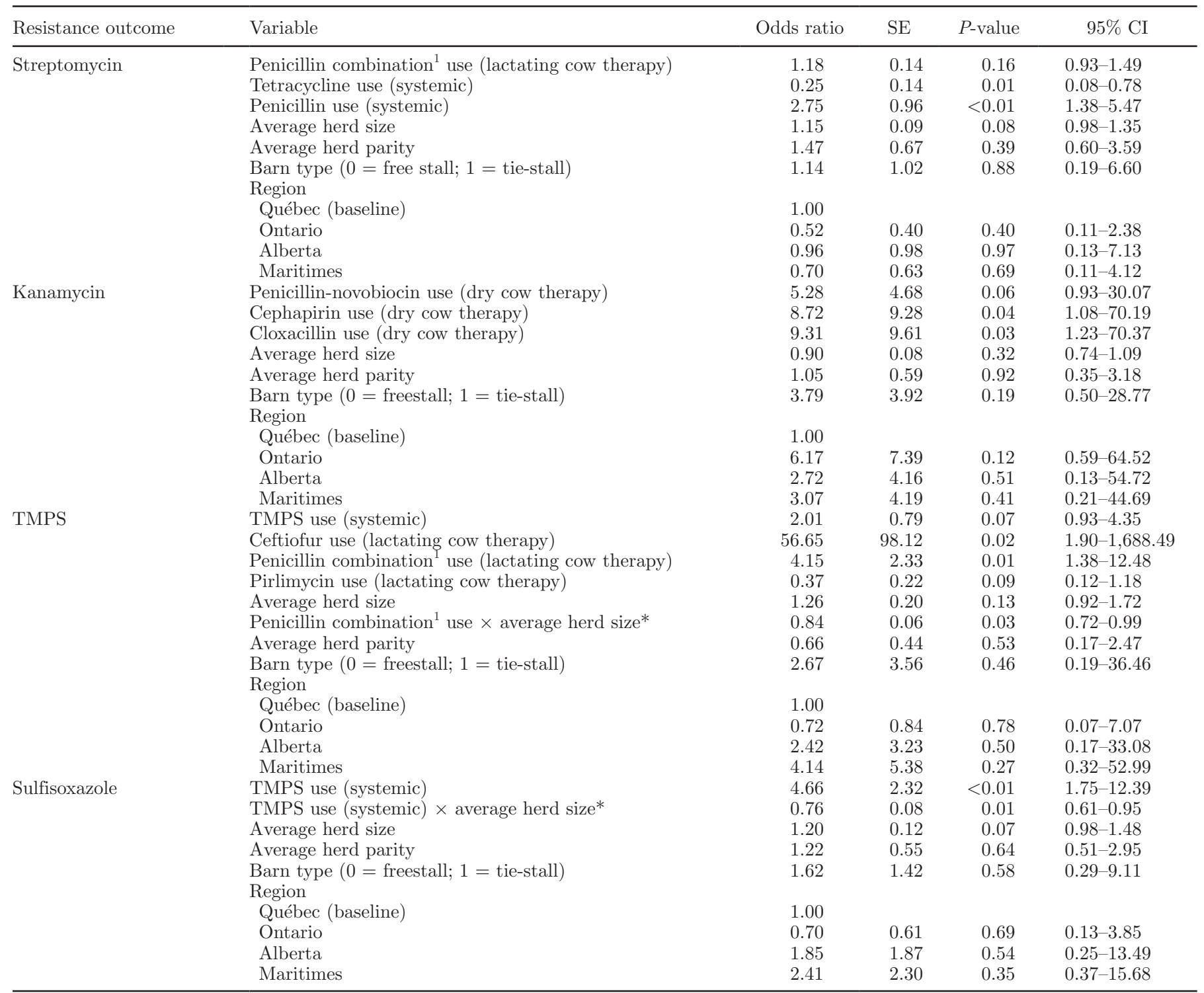

${ }^{1}$ Intramammary preparation containing penicillin $\mathrm{G}$ procaine, dihydrostreptomycin sulfate, novobiocin sodium, and polymyxin B sulfate.

*Interaction between explanatory variables.

of isolates (postclinical mastitis treatment isolates) cannot be included in the model as an independent predictor, and (b) with the current sample size of 76 herds, the study did not have adequate power to detect differences in herd-level AMR due to variation in average number of postclinical isolates across herds. Also, wider confidence intervals were observed for most herdlevel estimates. This suggests that sample size of herds needs to be increased in future studies so as to improve the precision of the effect estimates. Further, the assessment of how well the model fits the observed data was done using the Hosmer-Lemeshow goodness-of-fit test (Dohoo et al., 2009). Statistically significant differences between the observed and predicted probabilities of various AMR outcomes were not observed, thereby indicating that the models fit the observed data.

A similar study in these same herds determined the impact of herd-level AMU for mastitis treatment and control on AMR in bovine mastitis Staphylococcus aureus isolates (Saini et al., 2012c). Researchers reported that the use of penicillin-novobiocin combination for dry cow therapy was positively associated with penicillin and ampicillin resistance in Staph. aureus isolates; systemic administration of penicillin was positively 
Table 7. Final logistic regression models depicting herd-level association between antimicrobial use and antimicrobial resistance to cefoxitin and chloramphenicol in Escherichia coli $(\mathrm{n}=394)$ isolated from bovine IMI and (sub)clinical mastitis cases on 76 dairy farms in 6 Canadian provinces

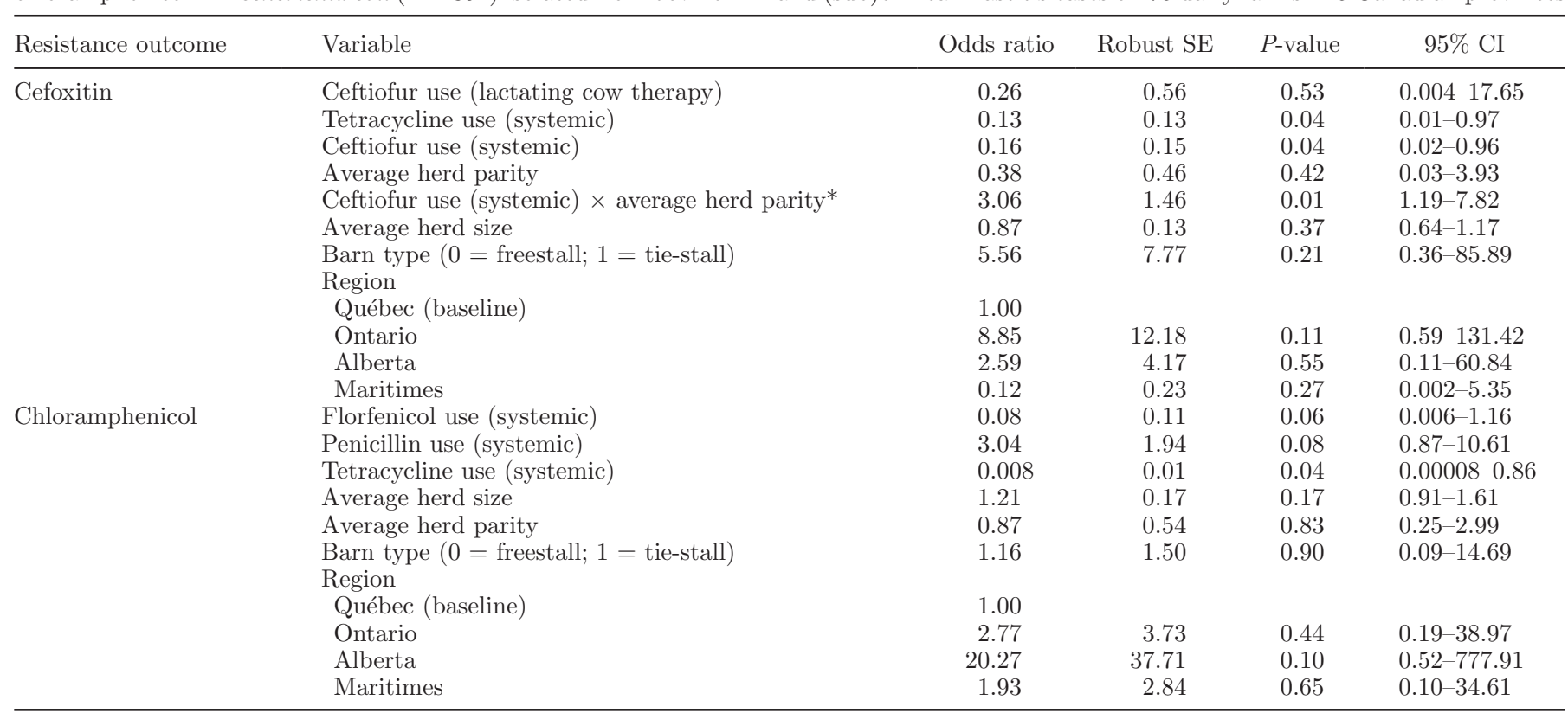

*Interaction between explanatory variables.

associated with penicillin resistance as well. Similar results suggesting direct effects, cross-resistance, and co-selection due to therapeutic and prophylactic use of antimicrobials were also observed in gram-negative bovine mastitis pathogens in the present study.

Herd-level associations suggesting potential crossresistance to certain antimicrobials were observed (e.g., the use of $\beta$-lactams such as ceftiofur administered intramammarily for lactating cow therapy; penicillinnovobiocin combination, cloxacillin, and cephapirin administered intramammarily for dry cow therapy; and penicillin administered systemically at a dairy farm were positively associated with herd-level ampicillinintermediate or -resistant E. coli isolates). In general, inactivating enzymes such as Temoniera (TEM)-type $\beta$-lactamases are widespread in enterobacteria that readily hydrolyze aminopenicillins such as ampicillin (Prescott, 2006a). Herd-level use of systemically administered TMPS was suggestive of potential crossresistance to sulfisoxazole in $E$. coli isolates. Intramuscular injection of TMP-sulfadoxine is an approved antimicrobial for lactating dairy cattle in Canada and is commonly used; however, it has poor udder penetration due to low bioavailability (Prescott, 2006b), and could potentially select sulfisoxazole resistant strains. Linkage between resistance determinants of sulfonamides (sul1 and sul2 genes) and TMP ( $d f r 1$ gene) or streptomycin (aadA1a) is commonly observed in enteric bacteria (Lanz et al., 2003).
Some herd-level associations suggested potential coselection as well. For example, the use of ceftiofur and penicillin combination containing dihydrostreptomycin administered intramammarily for lactating cow therapy was positively associated with TMPS-intermediate or -resistant coliforms. Multidrug resistance to ceftiofur, ampicillin, streptomycin, and TMPS has been observed in bovine mastitis E. coli isolates (Saini et al., 2012b). Class I integrons containing $\beta$-lactam, streptomycin, and TMP resistance-encoding genes have been isolated from multidrug-resistant $E$. coli isolates recovered from dairy cattle and the dairy farm environment (including calves, milk filters, overshoes, water sampled, swabs of the calf pen, and feeding bucket) on 21 dairy farms in Ireland in a recent study (Karczmarczyk et al., 2011). In fact, the majority of coliforms are from the gut, which are shed into the cow's environment and infect the udder via the teat canal (Lehtolainen et al., 2003). We suggest that several the $E$. coli isolates found in the milk samples of low-SCC cows were likely contaminants rather than mastitis pathogens in the present study. Compared with the gastrointestinal tract, the environment inside the udder is virtually sterile where no indigenous bacterial flora is present (Werckenthin et al., 2001). It is, therefore, quite plausible, that selection of AMR occurred inside the gut environment due to AMU in nonmastitic conditions.

Further, herd-level use of systemically administered penicillin suggested possible selection for streptomycin- 
intermediate or -resistant E. coli isolates, whereas dihydrostreptomycin-containing penicillin combinations administered intramammarily for lactating cow therapy were not associated with streptomycin-intermediate or -resistant E. coli. Streptomycin/dihydrostreptomycin is synergistic with penicillin in the case of gram-positive bacteria, but is usually not synergistic against the gramnegative bacteria (Dowling, 2006). However, it is quite likely that when dihydrostreptomycin-containing penicillin combinations are used, only the dihydrostreptomycin component is associated with streptomycin resistance, and penicillin has no effect per se. Unfortunately, it is not possible to attribute streptomycin resistance to the use of dihydrostreptomycin alone in this study due to its presence with penicillin in a combination product. Use of cephapirin and cloxacillin for dry cow therapy was associated with kanamycin-intermediate or -resistant E. coli in the present study as well. Use of penicillins was associated with kanamycin resistance in fecal E. coli isolated from swine farms (Akwar et al., 2008). It is likely that the use of penicillins is coselecting plasmids with $\beta$-lactam and aminoglycoside resistance genes.

Interestingly, the association of systemic use of ceftiofur with cefoxitin resistance was modified by average herd parity (i.e., the odds of cefoxitin-intermediate or -resistant E. coli due to systemic use of ceftiofur increased with an increase in parity). For example, older herds may have a greater rate of mastitis and, thus, use more antimicrobials. Age or BW could also influence relative systemic availability of an antimicrobial and that could potentially affect AMR as well (Marshall and Palmer, 1980). Average herd size modified the association of penicillin combination used for lactating cow therapy with TMPS-intermediate or -resistant $E$. coli isolates (i.e., the odds of TMPS-intermediate or -resistant $E$. coli due to penicillin combination use decreased with an increase in herd size). Similarly, the odds of sulfisoxazole-intermediate or -resistant E. coli due to systemically administered TMPS use decreased with an increase in herd size. Herd size could be a surrogate to certain factors that are yet to be identified in AMR epidemiology. Strangely, negative associations between antimicrobial use and resistance were observed for certain antimicrobials. For example, the use of systemically administered tetracycline and ceftiofur was associated with decreasing odds of cefoxitin-intermediate or -resistant E. coli. Negative associations appear to be biologically implausible and, therefore, such observations could be spurious. However, inverse associations may indicate potentially incompatible resistance determinants or factors that might be surrogate for other risk factors yet to be identified in AMR epidemiology (Akwar et al., 2008).
The experimental unit in the current study was the farm and not an individual cow. Antimicrobial resistance is potentially a herd-level phenomenon, as farm ecosystems provide an ideal environment for emergence, amplification, and dissemination of resistant bacteria/ determinants (Acar and Moulin, 2006). In the case of bovine mastitis coliforms, it was hypothesized that selection of AMR occurs outside the bovine udder due to the presence of antimicrobials or AMR bacteria in the feces of animals in a dairy farm environment (Burgos et al., 2005; Hammad et al., 2008). The objective in the current study was to assess and evaluate dynamics of AMR (intermediate or resistant) at the herd level; hence, antimicrobial use was not determined at the individual cow level. Therefore, no inferences can be made at the individual cow level. The present study was a cross-sectional snapshot of AMU and AMR in bovine mastitis pathogens and does not reflect temporal changes. Such group-level studies are exploratory in nature, as no direct measure exists of the exposure of interest due to measurement constraints at the individual cow level (Dohoo et al., 2009). These studies are primarily hypothesis generating in nature and cannot assess a causal relationship between AMU and AMR due to the cross-sectional and ecological nature of the study. Instead, prospective individual cow-level cohort studies are a powerful design to assess and evaluate causal relationship between AMU and AMR in bacteria. Bovine mastitis pathogen-specific MIC breakpoints are only available for pirlimycin, ceftiofur, and penicillin-novobiocin combination; interpretive criteria for remaining antimicrobials are either derived from human data (CLSI, 2000) or other veterinary-specific indicated organisms isolated from designated animal species (with defined disease; CLSI, 2008). Therefore, the results of our study should be interpreted cautiously. Further, multidrug resistance was commonly observed among bovine mastitis coliforms (Saini et al., 2012b). However, the present study design was unable to assess and evaluate modifiable determinants of multidrug resistance because the number of farms exhibiting various multidrug resistance patterns was too low to detect a difference in multidrugresistance prevalence. Therefore, the study was designed to measure association between nonsusceptibility (intermediate or resistant isolates) to a single antimicrobial and antimicrobial use. Furthermore, an ideal herd-level analysis would have been an ordinal logistic regression in which farms would be classified as susceptible, intermediate, or resistant according to mutually exclusive criteria. However, such classification was not possible in the present study because some herds had both intermediate and resistant isolates. Therefore, to facilitate ordinary logistic regression analysis, intermediate isolates were merged with the resistant category. 


\section{CONCLUSIONS}

Presence or absence of AMR in bovine mastitis $E$. coli isolates at the herd level was associated with the use of antimicrobials commonly administered on Canadian dairy farms. The use of $\beta$-lactams was associated with increasing odds of $E$. coli being intermediate or resistant to ampicillin, aminoglycoside, and TMPS. In addition to AMU data, information should also be collected on dairy practices related to bedding and udder hygiene that could potentially affect AMR in bovine mastitis pathogens.

\section{ACKNOWLEDGMENTS}

The authors thank technicians Adele Veinot, Andrea Wasko, Anke Wellen, Francois Dubois, Meliza Morris, Mike MacLean, Natasha Robinson, and Theresa Andrews for collection of drug tally sheets, Matthew Saab and Cynthia Mitchell (all from Canadian Bovine Mastitis Research Network, St-Hyacinthe, QC, Canada) for all laboratory analyses, Vicky Stagg (University of Calgary, Calgary, AB, Canada) for statistical programming, and Jean-Philippe Roy, Luc DesCôteaux, Ian Dohoo, Greg Keefe, and Kristen Reyher (all from Canadian Bovine Mastitis Research Network) for coordination of the National Dairy Farm Cohort regional centers. This research was financed by the Natural Science and Engineering Research Council of Canada (Ottawa, ON, Canada); Alberta Milk (Edmonton, AB, Canada); Dairy Farmers of New Brunswick (Sussex, NB, Canada), Nova Scotia (Lower Truro, NS, Canada), Ontario (Mississauga, ON, Canada), and Prince Edward Island (Charlottetown, PE, Canada); Novalait Inc. (Québec, QC, Canada), Dairy Farmers of Canada (Ottawa, ON, Canada), Canadian Dairy Network (Guelph,, ON, Canada), Agriculture and Agri-Food Canada (Ottawa,, ON, Canada), Public Health Agency of Canada (Ottawa,, ON, Canada), Technology PEI Inc. (Charlottetown, PE, Canada), Université de Montréal (Montréal, QC, Canada), and University of Prince Edward Island (Charlottetown, PE, Canada), through the Canadian Bovine Mastitis Research Network (Saint-Hyacinthe, Qc, Canada).

\section{REFERENCES}

Acar, J. F., and G. Moulin. 2006. Antimicrobial resistance at farm level. Rev. Sci. Tech. 25:775-792.

Akwar, H. T., C. Poppe, J. Wilson, R. J. Reid-Smith, M. Dyck, J. Waddington, D. Shang, and S. A. McEwen. 2008. Associations of antimicrobial uses with antimicrobial resistance of fecal Escherichia coli from pigs on 47 farrow-to-finish farms in Ontario and British Columbia. Can. J. Vet. Res. 72:202-210.

Barkema, H. W., Y. H. Schukken, T. J. G. M. Lam, M. L. Beiboer, H. Wilmink, G. Benedictus, and A. Brand. 1998. Incidence of clinical mastitis in dairy herds grouped in three categories by bulk milk somatic cell counts. J. Dairy Sci. 81:411-419.

Berge, A. C. B., E. R. Atwill, and W. M. Sischo. 2005. Animal and farm influences on the dynamics of antibiotic resistance in faecal Escherichia coli in young dairy calves. Prev. Vet. Med. 69:25-38.

Berge, A. C., D. D. Hancock, W. M. Sischo, and T. E. Besser. 2010 Geographic, farm, and animal factors associated with multiple antimicrobial resistance in fecal Escherichia coli isolates from cattle in the western United States. J. Am. Vet. Med. Assoc. 236:1338 1344 .

Burgos, J. M., B. A. Ellington, and M. F. Varela. 2005. Presence of multidrug-resistant enteric bacteria in dairy farm topsoil. J. Dairy Sci. 88:1391-1398.

Checkley, S. L., J. R. Campbell, M. Chirino-Trejo, E. D. Janzen, and J. J. McKinnon. 2008. Antimicrobial resistance in generic fecal Escherichia coli obtained from beef cattle on arrival at the feedlot and prior to slaughter, and associations with volume of total individual cattle antimicrobial treatments in one western Canadian feedlot. Can. J. Vet. Res. 72:101-108.

CLSI (Clinical and Laboratory Standards Institute). 2000. Performance standards for antimicrobial susceptibility testing. 12th Informational Supplement. M100-S14. CLSI, Wayne, PA.

CLSI (Clinical and Laboratory Standards Institute). 2008. Performance Standards for Antimicrobial Disk and Dilution Susceptibility Tests for Bacteria Isolated From Animals; Approved Standard-Third Edition. M31-A3. Pages 65-72. CLSI, Wayne, PA.

Dohoo, I. R., W. Martin, and H. Stryhn. 2009. Veterinary Epidemiologic Research. 2nd ed. VER Inc., Charlottetown, PEI, Canada.

Dohoo, I. R., J. Smith, S. Andersen, D. F. Kelton, S. Godden, and Mastitis Research Workers' Conference. 2011. Diagnosing intramammary infections: Evaluation of definitions based on a single milk sample. J. Dairy Sci. 94:250-261.

Dowling, P. M. 2006. Aminoglycosides. Page 214 in Antimicrobial Therapy in Veterinary Medicine. S. Giguère, J. F. Prescott, J. D. Baggot, R. D. Walker, and P. M. Dowling, ed. Blackwell Publishing, Ames, IA.

Erskine, R. J., P. C. Bartlett, J. L. VanLente, and C. R. Phipps. 2002. Efficacy of systemic ceftiofur as a therapy for severe clinical mastitis in dairy cattle. J. Dairy Sci. 85:2571-2575.

Erskine, R. J., R. C. Wilson, M. G. Riddell Jr., J. W. Tyler, H. J. Spears, and B. S. Davis. 1992. Intramammary administration of gentamicin as treatment for experimentally induced Escherichia coli mastitis in cows. Am. J. Vet. Res. 53:375-381.

Hammad, A. M., A. M. Ahmed, Y. Ishida, and T. Shimamoto. 2008. First characterization and emergence of SHV-60 in raw milk of a healthy cow in Japan. J. Vet. Med. Sci. 70:1269-1272.

Hogan, J. S., R. N. Gonzalez, R. Harmon, S. C. Nickerson, S. P. Oliver, J. W. Pankey, and K. L. Smith. 1999. Laboratory Handbook on Bovine Mastitis. National Mastitis Council Inc., Verona, WI.

Hosmer, D. W., and S. Lemeshow. 2000. Applied Logistic Regression. 2nd ed. John Wiley \& Sons Inc., Hoboken, NJ.

Jensen, V. F., E. Jacobsen, and F. Bager. 2004. Veterinary antimicrobial-usage statistics based on standardized measures of dosage. Prev. Vet. Med. 64:201-215.

Karczmarczyk, M., Y. Abbott, C. Walsh, N. Leonard, and S. Fanning. 2011. Characterisation of multidrug resistant Escherichia coli from animals presenting at a university veterinary hospital. Appl. Environ. Microbiol. 77:7104-7112.

Lanz, R., P. Kuhnert, and P. Boerlin. 2003. Antimicrobial resistance and resistance gene determinants in clinical Escherichia coli from different animal species in Switzerland. Vet. Microbiol. 91:73-84.

Lehtolainen, T., A. Shwimmer, N. Y. Shpigel, T. Honkanen-Buzalski, and S. Pyörälä. 2003. In vitro antimicrobial susceptibility of Escherichia coli isolates from clinical bovine mastitis in Finland and Israel. J. Dairy Sci. 86:3927-3932.

Makovec, J. A., and P. L. Ruegg. 2003. Antimicrobial resistance of bacteria isolated from dairy cow milk samples submitted for bacterial culture: 8,905 samples (1994-2001). J. Am. Vet. Med. Assoc. 222:1582-1589.

Marshall, A. B., and G. H. Palmer. 1980. Injection sites and drug bioavailability. Page 54 in Trends in Veterinary Pharmacology and 
Toxicology. A. S. J. P. A. M Van Miert, J. Frens, and F. W. van der Kreek ed. Elsevier Publishing Co., Amsterdam, the Netherlands.

Olde Riekerink, R. G. M., H. W. Barkema, D. F. Kelton, and D. T. Scholl. 2008. Incidence rate of clinical mastitis on Canadian dairy farms. J. Dairy Sci. 91:1366-1377.

Prescott, J. F. 2006a. Beta-lactam antibiotics: Penam penicillins. Page 124 in Antimicrobial Therapy in Veterinary Medicine. S. Giguère, J. F. Prescott, J. D. Baggot, R. D. Walker, and P. M. Dowling, ed. Blackwell Publishing, Ames, IA.

Prescott, J. F. 2006b. Sulfonamides, diaminopyrimidines, and their combinations. Page 260 in Antimicrobial Therapy in Veterinary Medicine. S. Giguère, J. F. Prescott, J. D. Baggot, R. D. Walker, and P. M. Dowling, ed. Blackwell Publishing, Ames, IA.

Pyörälä, S., and T. Honkanen-Buzalski. 1994. The status of mastitis in the Nordic countries. Int. Dairy Fed. Mastitis News 19:14-15.

Pyörälä, S., L. Kaartinen, H. Käck, and V. Rainio. 1994. Efficacy of two therapy regimens for treatment of experimentally induced Escherichia coli mastitis in cows. J. Dairy Sci. 77:453-461.

Reyher, K. K., S. Dufour, H. W. Barkema, L. Des Côteaux, T. J. Devries, I. R. Dohoo, G. P. Keefe, J.-P. Roy, and D. T. Scholl. 2011. The National Cohort of Dairy Farms - A data collection platform for mastitis research in Canada. J. Dairy Sci. 94:16161626.

Saini, V., J. T. McClure, D. Léger, S. Dufour, A. G. Sheldon, D. T. Scholl, and H. W. Barkema. 2012a. Antimicrobial use on Canadian dairy farms. J. Dairy Sci. 95:1209-1221.

Saini, V., J. T. McClure, D. Léger, G. P. Keefe, D. T. Scholl, D. W. Morck, and H. W. Barkema. 2012b. Antimicrobial resistance pro- files of common mastitis pathogens on Canadian dairy farms. J. Dairy Sci. 95:4319-4332.

Saini, V., J. T. McClure, D. T. Scholl, T. J. DeVries, and H. W. Barkema. 2012c. Herd-level association between antimicrobial use and antimicrobial resistance in bovine mastitis Staphylococcus aureus isolates on Canadian dairy farms. J. Dairy Sci. 95:1921-1929.

Shpigel, N. Y., M. Winkler, G. Ziv, and A. Saran. 1998. Clinical, bacteriological and epidemiological aspects of clinical mastitis in Israeli dairy herds. Prev. Vet. Med. 35:1-9.

Srinivasan, V., B. E. Gillespie, M. J. Lewis, L. T. Nguyen, S. I. Headrick, Y. H. Schukken, and S. P. Oliver. 2007. Phenotypic and genotypic antimicrobial resistance patterns of Escherichia coli isolated from dairy cows with mastitis. Vet. Microbiol. 124:319-328.

Wagner, S., and R. Erskine. 2006. Antimicrobial drug use in bovine mastitis. Page 511 in Antimicrobial Therapy in Veterinary Medicine. S. Giguère, J. F. Prescott, J. D. Baggot, R. D. Walker, and P. M. Dowling, ed. Blackwell Publishing, Ames, IA

Werckenthin, C., M. Cardoso, J.-L. Martel, and S. Schwarz. 2001 Antimicrobial resistance in staphylococci from animals with particular reference to bovine Staphylococcus aureus, porcine Staphylococcus hyicus, and canine Staphylococcus intermedius. Vet. Res. $32: 341-362$

Zadoks, R. N., and M. A. Munoz. 2007. The emergence of Klebsielle as a major mastitis organism. Pages $100-111$ in Proc. NMC 46th Annual Meeting, San Antonio, TX. National Mastitis Council Inc. Verona, WI. 